\title{
Investigating health factors as predictor of early drop-out of first year accounting students at the University of the Free State, South Africa
}

\author{
Christa Beyers, Hanli Joubert
}

School of Education Studies, University of the Free State, South Africa

\begin{abstract}
Introduction: The future of the South African workforce looks bleak given the challenges posed, not only by health factors, including HIV and AIDS, but also the success and throughput rate of first year university students.

Methodology: The research in this study was conducted in 2013 using a post-positivist approach and applying an interpretive stance using a mixed method approach, which included a quantitative non-experimental predictive multivariate design as well as focus group interviews to triangulate the findings.

Results: We present findings that psychosocial background factors, physical health and emotional health influence success and non-completion rates among first year students at the University of the Free State, South Africa.

Conclusion: We argue that early identification of poor psychosocial background, including health factors, can assist in empowering youths helping them to make healthy decisions and deal with stressful situations in a way that will not compromise their academic success.
\end{abstract}

Key words: health factors, success, non-completion, psychosocial background, HIV and AIDS

\section{Introduction}

National and international research findings indicate a problem with student success and non-completion rates in higher education studies in general (Seidman, 2005: xii; Steenkamp, Baard \& Frick, 2009: II3). According to Tinto (in Horstmanshof \& Zimitat, 2007: 704), non-completion rates are generally highest in students' first year of study at university. In South Africa, the average throughput rate for first-year Accounting students raises concern. At the University of the Free State (UFS) the average throughput rate between 2004 and 2008 has been 54\% (Joubert, Viljoen \& Schall, 2013), whereas Steenkamp, Baard and Frick (2009: II6) report the throughput rate at the University of Stellenbosch to have been almost $70 \%$ for the past number of years. Du Plessis, Müller and Prinsloo (2005: 684) report a throughput rate of less than $33 \%$ for distance education 
first-year Accounting students at the University of South Africa. Graduating at a higher institution must be viewed as a possibility that provides youths with the prospect of a meaningful and successful life. Although some students are able to experience the transition from school to university as positive, others seem to be overwhelmed by the changes, especially when faced by challenges experienced in their personal lives.

When students experience problems with their physical and emotional health, they are not able to attend classes and to study effectively. In fact, DeBerard, Spielmans and Julka (2004: 66) found that certain physical health variables were related to retention in tertiary education. Many diseases are the cause of chronic illness, and at the same time HIV and AIDS which has reached epidemic proportions in South Africa, must be viewed as a contributing factor to the early drop-out rate of first year university students. Shisana, Rehle, Simbayi, Zuma, Jooste, Zungu, Labadarios, Onoya et al. (2014:42) state that in spite of all the efforts to prevent infection, HIV is still escalating amongst young people.

The Joint United Nations Programme on HIV/AIDS (UNAIDS) (2014:17) asserts that globally, fifteen (I5) countries account for nearly $75 \%$ of all people living with HIV, as outlined in Figure I below.

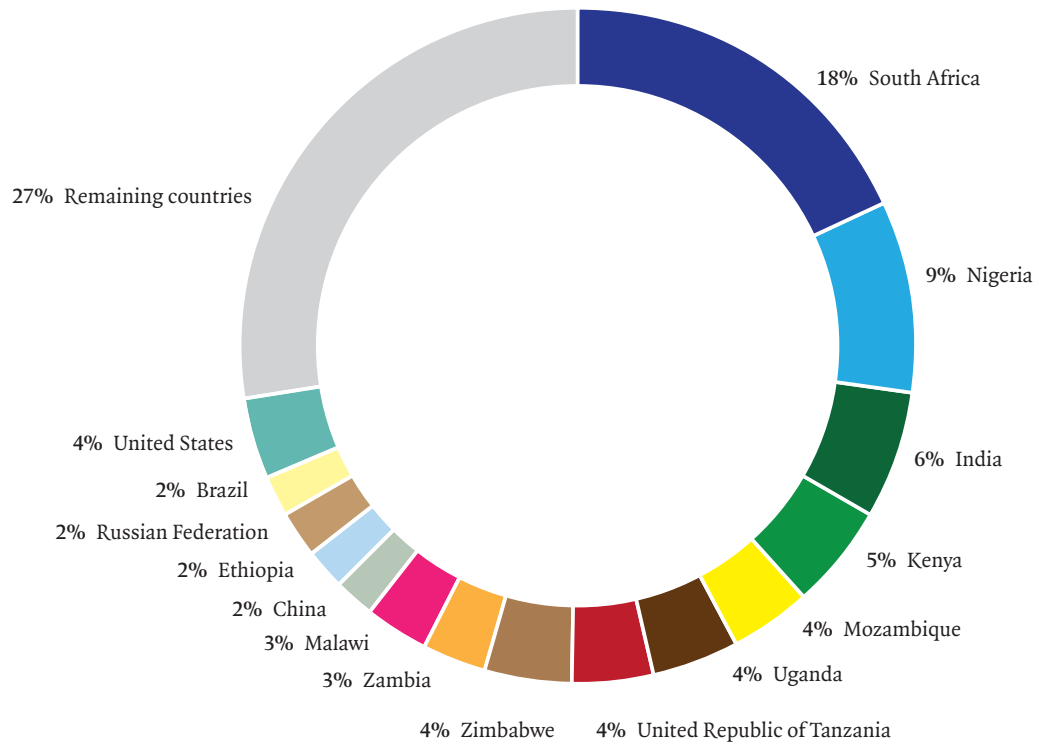

Figure 1: People living with HIV by country, 2013 (source UNAIDS 2013 estimates)

The Higher Education HIV/AIDS Programme (HEAIDS) (2010) declares that of the total population aged I5 years and older, 5.4 million people were estimated to be HIVpositive in South Africa. Among 20-24 year olds the prevalence was $16.5 \%$. Whether a 
student is infected or affected by the disease, the associated challenges can leave first year students unable to manage the personal, social and academic aspects of their lives.

Breier (2010: 665) states that staff members at the University of the Western Cape, South Africa, reported HIV and AIDS as a cause for early drop-out and students being absent from lectures on account of illness. Of interest is that students themselves did not mention that their own health or that of a family member contributed to early drop-out. This could be an indication that students stay away from class or drop out of higher education because of the stigmatisation they experience. In addition, dropout is associated with early and unsafe sexual behavior (World Bank, 2002).

The HIV and AIDS pandemic not only affects the physical health of students, but may also impact on their emotional health (Leslie, Stein \& Rotheram-Borus (2002). The stress caused by the fear of having contracted the disease also affects student performance. Many students avoid HIV testing because of fear; and living with this fear, in turn, causes prolonged stress. Students may also be affected through the stress endured when family members are HIV-positive. Students might be expected to take care of HIV and AIDS-infected family members. When the parents of students die from AIDS these students are left to take care of siblings, making it difficult to study and attend lectures. All these HIV and AIDS-related factors result in lower student performance and noncompletion. Because so many students are affected by HIV and AIDS, as sufferers themselves or through their family members or relatives, it must be viewed as an important factor towards non-completion at university.

\section{Rationale for the study}

First-year Accounting is a compulsory subject for most Bachelor of Commerce (BCom) degrees at University level. This implies that, in most cases, students have to pass at least first-year Accounting to obtain their degrees. Consequently, research into the factors contributing to success and non-completion in first-year Accounting could prove to be informative. Extensive research has been conducted on factors that could influence the success or non-completion of students in general, and on a Accounting students in particular (Elias, 2005; Halabi, Tuovinen \& Farley, 2005; Jackling, 2005; Visser, McChlery \& Vreken, 2006), and on the other hand many other determinants of success and non-completion have been researched and contradictory findings reported. These determinants include age, gender, prior knowledge of Accounting, prior knowledge of mathematics, language proficiency and pedagogical techniques (Levy \& Murray, 2005; Tickell \& Smyrnios, 2005). Very little research focused on health factors which include being affected or infected with HIV. Added to this, there are the emotional consequences of HIV and AIDS such as stress, depression and disconnectedness.

This research has expanded on the existing body of knowledge on the predictors of success and non-completion in first-year students. It specifically provides answers to the following research question:

Do health factors, including HIV and AIDS, influence success and non-completion in first year Accounting students? 
Subsidiary research questions that emerged are:

How are the students affected by health factors? What can be done to assist first year students in successful completion of their studies?

\section{Methodology}

\section{Research design}

The research in this study was conducted using a partially mixed sequential equal status design (Leech \& Onwuegbuzie, 2009) which included a quantitative non-experimental predictive multivariate design as well as focus group interviews to triangulate the findings. The study was conducted using two phases that occurred sequentially, with the quantitative and qualitative phases having equal weight. Quantitative research searches for relationships between variables and it may also explain the relationships between different variables (Fraenkel \& Wallen, 2008: I5), whereas qualitative research aims to seek answers by collecting evidence. The rationale for using both these methods was to firstly assess whether health factors have a significant effect on the low throughput rate of first year students, and if so, how the students are affected by these factors. Although this paper focuses on health-related factors, variables such as age, gender and ethnicity were included in the initial design to try and predict the interdependence between multiple independent variables and the dependent variable, namely performance in first-year Accounting. The following instrument was applied in this study.

\section{Psychosocial Questionnaire (PSQ)}

The PSQ was developed by Viljoen in 2007. This questionnaire is used for the measurement of psychosocial background factors relating to the subjects' childhood and present situation. It consists of $\mathrm{I} 9$ items on a semantically differentiated scale which collects information on the emotional support and the socio-economic situation of the subject's childhood, as well as the conduciveness of the childhood environment to learning and depression. The respondent's present life situation is measured with regard to financial situation, love life, family life, depression as well as HIV and AIDS.

According to Fraenkel and Wallen (2008: I48), validity can be referred to as ' ... the degree to which evidence supports any inferences the researcher makes based on the data he or she collects using a particular instrument. Construct validity refers to how well a measure of the construct explains differences in the behaviour of individuals or their performance on certain tasks'. The reason why the PSQ was used is because a literature study revealed that many of the factors influencing the academic performance of students form part of the group of factors measured by the PSQ. The PSQ therefore has construct validity, because the ig items of the questionnaire are grounded in the literature regarding psychosocial background factors.

The PSQ demonstrated high reliability with a Cronbach alpha-coefficient of 0.82 in a pilot study (Viljoen, 2007). The PSQ therefore showed internal consistency which indicates adequate reliability. A high score on the PSQ indicates that respondents have a negative psychosocial background, while a low score on the PSQ indicates that respondents have a positive psychosocial background. 
For the second phase focus group interviews were employed with the aim of capitalzing on communication between participants in order to generate data (Berg \& Lune, 20I2). Focus group interviews were chosen as they facilitated discussion of a sensitive topic (health factors including HIV and AIDS) and clarify the findings regarding health factors that were obtained in thequantitative part of the study. The group discussion was unstructured in order to elicit the participants' true feelings and reflections on how they were affected by health factors with regard to their academic achievement.

\section{Participants and sampling}

The population refers to the group that is relevant to the researcher's study and to whom the findings of the study would be generalised (Fraenkel \& Wallen, 2008: 9I). The population under study (target population) in the quantitative part of the study comprised 553 of a possible I 57 first-year Accounting students.

Consent to obtain information from the first year students and their performance in Accounting I (REKII4) as well as permission to conduct the research was obtained from the Ethics Committee of the Faculty of Education. Students were briefed about the aim and purpose of the study, and the researchers respected the right of students who chose not to participate in the study or to withdraw from participating at any time. Five hundred and fifty three students were willing to participate in the first phase of the study and thus represented the accessible population. This implies a response rate of $48 \%$. The reason why only $48 \%$ of the first-year Accounting students participated in the study was due to poor class attendance (students did not know beforehand that they would be asked to participate in the study) and because a number of students were not willing to participate.

Students who participated in phase one, were invited to take part in focus group interviews. Only 2I volunteered to participate in the interviews. Three sessions were scheduled with the participants. Students were assured that all data obtained would be treated as confidential. Participants were briefed about the scope of the study and no deception took place. Full anonymity was ensured with the option to withdraw from the study at any time.

\section{Data analysis and reporting}

The main aim of the study was to establish whether health factors could influence success and non-completion in the first year of study. Three sources of variability, namely systematic variance, error variance and confounding variance were recognized and controlled in the research design by applying the principle of MAXIMINCON (McMillan \& Schumacher, 2006). Median or confounding variables, such as age, gender and ethnicity were included in the questionnaire as these factors could also influence results, and therefore were taken into consideration. Data for the quantitative questionnaire was categorized and coded (Kerlinger, I986) by the researchers and then recorded by the Department of Information and Technology Services. This department then analysed the data quantitatively, making use of the Statistical Analysis Plan developed by Professor Schall from the Statistics Department of the UFS (Schall personal communication, 2009; 2010). 
The software programme, SAS Proc GLM, was used for multivariate analysis. For the second phase an interpretive approach was followed when analysing the data. Data were recorded, transcribed and interpreted in order to identify themes that were pointed out by the students as proposed by Tesch (in Creswell, 1994). Answers that emerged in the interviews were interpreted by means of inductive reasoning with the aim to include all feelings and ideas of the participants.

\section{Results}

The results obtained in the quantitative phase of the study are presented in tabular and written form, and will be discussed in the next section. Table I has been created to summarize the performance of respondents.

\begin{tabular}{l|l|l|l|l|l|l|l} 
Variable & N & N Miss & Mean & Std Dev & Minimum & Maximum & Median \\
\hline REK114 & 553 & 0 & 44.42 & 22.89 & 0.00 & 97.00 & 50.00
\end{tabular}

Table 1: Performance in Accounting

The mean of the final mark in Accounting, obtained by the sample of 553 respondents, was $44.42 \%$, while the median was $50 \%$. The median is higher than the mean and therefore the normal distribution is negatively skewed. This implies that the number of students who obtained a mark above $44.42 \%$ was more than the number of students who obtained a mark below $44.42 \%$. An average of $44.42 \%$ for first-year Accounting is, however, inadequate as students need a mark of $50 \%$ to pass.

\begin{tabular}{l|l|l|l|l|l|l|l} 
Variable & N & N Miss & Mean & Std Dev & Minimum & Maximum & Median \\
\hline Psychosocial Total & 551 & 2 & 40.90 & 14.97 & 19.00 & 99.00 & 38.00
\end{tabular}

Table 2: Psychosocial background distribution of the respondents in the sample (per total of PSQ) ( $n=551)$

(Frequency missing $=2$ )

The number of respondents who completed the PSQ (sample size) was 55I because two respondents did not complete the PSQ. The PSQ was designed as a six-point semantic differential type scale consisting of nineteen items, while the maximum score per item is six. Therefore, a maximum total score of II4 is possible. A high score indicates negative psychosocial circumstances, while a lower score indicates positive psychosocial circumstances. The total of the midpoints for nineteen items is 66.5 . The mean of this sample is 40.9 and the median is 38 , both of which are lower than the total midpoint. The Gaussian distribution (normal distribution curve) is positively skewed. This implies that more students in this sample have a favourable psychosocial background and that fewer students have an unfavourable psychosocial background. 


\begin{tabular}{l|l|l|l|l} 
Parameter & Estimate & Standard Error & T-Value & $\operatorname{Pr}>|\mathbf{t}|$ \\
\hline Intercept & 49.73000580 & 2.82689066 & 17.59 & $<.0001$ \\
\hline PsychoTotal & -0.12762272 & 0.06490899 & -1.97 & 0.0498
\end{tabular}

Table 3: Regression of Accounting on psychosocial background

According to the results indicated in Table 3, the impact of psychosocial background on the performance in Accounting is significant since a p-value of 0.0498 , which is lower than the $\mathrm{p}<0.05$ level of significance, was obtained. Lower scores on the PSQ reflect favourable psychosocial backgrounds, while higher scores on the PSQ reflect unfavourable psychosocial backgrounds. An inverse relationship exists between psychosocial background and performance in Accounting, because the t-value was -I.97. The inverse relationship indicates that students who scored high on the PSQ and experienced unfavourable psychosocial backgrounds obtained lower marks than students who scored low on the PSQ. Irrespective of the fact that the majority of students have a favourable psychosocial background, a significant inverse relationship between the psychosocial background and performance in Accounting exists.

When it was established that psychosocial background has a significant effect on academic performance, focus group interviews were conducted to answer the subsidiary research questions. In general, participants felt positive about participating in the study, but some wanted assurances that the interviews were confidential, as they viewed the topic as being sensitive. Participants were asked the following leading question: Do you view health factors, both physical and emotional, as contributing to poor academic achievement and early drop-out in the first year of study? All agreed that health factors contribute to poor academic performance. The following are some of the reflections from the qualitative findings. A variety of opinions were expressed, and results will be discussed under relevant themes.

\section{Theme 1: Physical health and HIV}

All participants mentioned that their personal relationships contributed to their academic success. They mentioned that it was very important in their first year of study to be accepted by their peers. Acceptance is often sought by becoming sexually active. Most students indicated that they are sexually active, but they are afraid to be tested for HIV, as they do not want to know if they are HIV positive.

"I would rather not know, it can only add to my stress..."

Of the 2I respondents, I7 reported that they either know, or are living with someone who is HIV positive. Those affected feel that they have emotional stress as they "worry about the people at home". Students who are affected, explained that their family members do not want to talk about the ill or infected person. This could be an indication that there is no willingness to talk about HIV and AIDS. Eleven of the participants indicated 
that their families would rather overlook, than talk about the illness and support the infected individual.

"...they would rather explain it away..."

This reaction creates a feeling of powerlessness in students as they believe it requires courage to disclose one's status. Participants raised the concern that if they were not informed, it implied that they themselves did not get the needed support with regard to their studies.

"We are kept in the dark... but it doesn't help. How are my needs met?"

Furthermore the person in denial may not take precautions to prevent the spread of the disease which then puts other people at risk of contracting HIV. Physical health and emotional health are therefore related in the sense that a healthy lifestyle contributes to a healthy body and mind.

\section{Theme 2: Stress}

Various factors may contribute to the stress that students and especially first-year students experience. Students reported that they experienced stress as they adjust to university and academic life. Most participants agreed that they are faced with numerous educational and personal stressors that may impact negatively on their physical and emotional health.

"I for one cannot even focus on my studies when I feel stressed, and my main thoughts are not on passing..."

Students reported that they do not feel motivated to achieve academically as they already find it difficult to manage their emotional and personal lives. However, stress is not the only factor that affects students' emotional well-being. Their well-being can also be affected by depression, which is discussed under theme 3 .

\section{Theme 3: Depression}

Academic underachievement, according to the participants, makes them feel depressed. Students are of the opinion that they are not worthy of studying at a university, especially if the family struggles financially.

"We have difficulties... not only financial, but if you have to care for the people at home, everyone expects more... people don't understand..."

Most students who feel that their difficulties are not recognized indicated that they do not get the necessary support. According to one participant, the lack of support led 
to their withdrawal from others. The feeling that no-one is supporting them transferred into anger in the majority of cases.

"If they cannot understand... then they think it is nonsense. There is no support because they are just selfish. I don't even want to know people like that."

Some participants also mentioned that there was indeed a time when they thought the best solution would be to take their own lives.

\section{Theme 4: Lack of support and self-esteem}

As mentioned in theme 3 , most participants feel that they would have a better chance of achieving academically if they received support not only from their families, but also from friends and the academic community. Participants mentioned that they sometimes feel "worthless".

Of the 2I students who took part in the focus group discussions, only 5 indicated that they received support from their families and friends. They indicated that they cope with stressors, and their academic achievement is also "acceptable". Although extended family members and significant others have an influence on the academic life of students, students' parents play a vital role in preparing their children for higher education and supporting their academic success.

\section{Discussion}

This research has expanded on the existing body of knowledge on the predictors of success and non-completion in first-year Accounting. It specifically attempted to provide answers to the stated research questions.

The findings in the quantitative phase of the study indicated that health factors and an unfavourable psychosocial background have a significant effect on performance in Accounting I (REKII4). This finding is supported by the findings of Eisenberg, Golberstein and Hunt (2009), and Dass-Brailsford (2005) who stated that health and financial problems play an important role in affecting academic achievement. According to these researchers, the challenges may cause students to discontinue their studies. Furthermore, health factors may have a negative influence on the academic performance of students because the physical difficulties that students experience directly or indirectly affect their studies due to the stress caused by such problems. The data emanating from focus group discussions made it clear that living with HIV and AIDS, stress, depression, and lack of support, contributed to low self-esteem and underachievement in the first year of study.

Whatever the reason for students' stress, this may influence academic performance (Zajacova, Lynch \& Espenshade, 2006: 678). Pritchard and Wilson (2003: 18-27) researched the relationship between emotional health and student performance and found a significant correlation. Students' emotional health is also related to their intention to drop out of tertiary education. Dusselier, Dunn, Wang, Shelley and Whalen (2005: I5) stated that 'stress is the foremost impediment to academic performance, outranking the 
other top ro impediments to learning, including cold, flu, sore throat, sleep difficulties, concern for a troubled friend or family member, and relationship difficulties'. This concurs with the findings of Ruthig, Hayes, Stupnisky and Perry (2009: 233-234) who are of the opinion that first-year students are presented with numerous challenges that some may experience as overwhelming and that these students may become overly stressed and ultimately depressed. HIV and AIDS is a prominent health concern in South Africa and few people are trained to cope with the social, psychological and educational consequences, such as stress, as indicated in the focus group discussions. This concurs with Ruthig et al. (2009) when they state that 'stress and depression are common elements of poor psychological well-being that can negatively impact college performance'. Participants mentioned that the difficulties they face are not recognised and this contributes to their becoming depressed. Hysenbagasi, Hass and Rowland (2005: I45) concur that students who suffer from moderate to severe depression may experience poor academic performance because depression has an effect on the cognitive processes associated with learning. Participants who were interviewed stated that they felt that no one understood or supported them. Elliot, Menard, Rankin, Elliot, Wilson and Huizinga (2006: 170) support this when they report that '... warmth and a positive affective climate are a prerequisites for high self-esteem, academic and social competence and better mental health'.

It is imperative that risk factors be identified across the range of health disparities to assist in developing interventions to address not only health factors such as stress, depression and the HIV pandemic, but also the through-put rate of first year students.

Bearing in mind the research findings, the following recommendations are made. Another research study where the PSQ is used should be conducted. In the proposed study, however, the questions should be analysed according to emotional support, socioeconomic situation and depression, or even according to each individual item appearing in the questionnaire. This should be done for both the current situation and the childhood years of the respondents. By doing so, more detailed information can be obtained with regard to specific psychosocial problems and the influence on performance in firstyear Accounting or on performance in general.

\section{Limitations of the study}

Although this study indicated valuable and interesting findings, the following limitations have to be acknowledged. The sample size used in the research was adequate. However, because convenience sampling was used instead of random sampling, the results cannot be generalised and are therefore limited to the selected group of students. Self-report inventories always pose implicit problems with regard to students not being comfortable in divulging personal information, students not being motivated to answer truthfully and students not clearly understanding what is required of them.

\section{References}

Berg, B. L. \& Lune, H. (20I2). Qualitative research methods for the social sciences. 8th ed. Boston: Pearson.

Breier, M. (2010). From 'Financial considerations' to 'poverty': towards a reconceptualization of the role of finances in higher education student drop out. Higher Education, 6o(6):657-670. 
Cresswell, J. W. (1994). Research Design: Qualitative and Quantitative Approaches. London: Sage.

Dass-Brailsford, P. (2005). Exploring resiliency: Academic achievement among disadvantaged black youth in South Africa. South African Journal of Psychology, 35(3):574-590.

De Berard, M.S., Spielmans, G. I., \& Julka, D. C. (2004). Predictors of academic achievement and retention among college freshman: A longitudinal study. College Student Journal, 38(I):66-80.

Dusselier, L., Dunn, B., Wang, Y., Shelley, I. M., \& Whalen, D. F. (2005). Personal, health, academic, and environmental predictors of stress for residence hall students. Journal of American College Health, 54(I):15-24.

Du Plessis, A., Müller, H., \& Prinsloo, P. (2005). Determining the profile of the successful first-year Accounting student. South African Journal of Higher Education, I9(4):684-698.

Eisenberg, D., Golberstein, E. \& Hunt, J.B. (2009). Mental Health and Academic Success in College. The B.E. Journal of Economic Analysis \& Policy, 9(I), ISSN (Online) I935-I682, DOI: 10.2202/1935-I682, September 2009.

Elias, R. Z. (2005). Students' approaches to study in introductory Accounting courses. Journal of Education for Business, March/April:194-I99.

Elliot, D. S., Menard, S., Rankin, B., Elliot, A., Wilson, W. J., \& Huizinga, D. (2006). Good kids from bad neighborhoods: Successful development in social context. Cambridge: University Press.

Fraenkel, J. R., \& Wallen N. E. (2008). How to design and evaluate research in education. 7 th edition. New York: McGraw-Hill.

Halabi, A. K., Tuovinen, J. E., \& Farley, A. A. (2005). Empirical evidence on the relative efficiency of worked examples versus problem-solving exercises in Accounting principles instruction. Issues in Accounting Education, 2O(I):2I-30.

Higher Education HIV/AIDS Programme (HEAIDS) (2010). HIV Prevalence and related Factors. Higher Education Sector Study South Africa, 2008-2009. Pretoria: HEAIDS.

Horstmanshof, L., \& Zimitat, C. (2007). Future time orientation predicts academic engagement among first-year university students. Educational Psychology, 77(3):703-193.

Hysenbagasi, A., Hass, S.L. \& Rowland, C.R. (2005). The impact of depression on the academic productivity of university students. The Journal of Mental Health Policy and Economics, 8: I45-I5I.

Jackling, B. (2005). Perceptions of the learning context and learning approaches: Implications for quality learning outcomes in Accounting. Accounting Education: An International Journal, I4(3):27I-29I.

Joubert, H., Viljoen, M. \& Schall, R. (2013). Performace of first-year Accounting students: does time-perspective matter? Acta Academia, 45(3):242-267.

Kerlinger, F. N. (I986). Foundations of behavioural research. 3 rd edition. Orlando: Holt, Rinehart \& Winston.

Leech, N. L., \& Onwuegbuzie, A. J. (2009). A typology of mixed methods research designs. Quality \& Quantity: International Journal of Methodology, 43, 265-275.

Leslie, M. B., Stein, J. A., \& Rotheram-Borus, M. J. (2002). The impact of coping strategies, personal relationships, and emotional distress on health-related outcomes of parents living with HIV or AIDS. Journal of Social and Personal Relationships (Special Issue: Personal and social relationships of individuals living with HIV and/or AIDS), I9, 45-66.

Levy, S., \& Murray, J. (2005). Tertiary entrance scores need not determine academic success: An analysis of student performance in an equity and access program. Journal of Higher Education Policy and Management, 27(I):I29-I40.

McMillan, J. H., \& Schumacher, S. (2006). Research in education: evidence-based inquiry. 6th edition. Boston:Pearson.

Pritchard, M. E., \& Wilson, G. (2003). Using emotional and social factors to predict student success. Journal of College Student Development, 44(I):I8-27.

Ruthig, J. C., Hayes, T. L., Stupnisky, R. H., \& Perry, R. P. (2009). Perceived academic control: Mediating the effects of optimism and social support on college students' psychological health. Social Psychology of Education, I2:233-249. 
Schall, R. (2009). Statistical analysis plan. Personal communication: I4 April 2009. Shisana, O., Rehle, T., Simbayi, L.C., Zuma, K., Jooste, S., Zungu, N., Labadarios, D., Onoya, D et al. (2014). South African National HIV Prevalence, Incidence and Behaviour Survey, 2012. Cape Town: HSCR Press.

Seidman, A. (2005). College student retention: Formula for student success. United States of America: American Council on Education/Praeger.

Steenkamp, L. P., Baard, R. S., \& Frick, B. L. (2009). Factors influencing success in first-year Accounting at a South African university: A comparison between lecturers' assumptions and students' perceptions. SA Journal of Accounting Research, 23(I):II3-I40.

Tickell, G. T., \& Smyrnios, K. X. (2005). Predictors of tertiary Accounting students' academic performance: A comparison of Year 12-to university students with TAFE-to-university students. Journal of Higher Education Policy and Management, 27(2):239-259.

Viljoen, M. (2007). Psychosocial Background Questionnaire. Unpublished document. CHED Library.

Visser, S., McChlery, S., \& Vreken, N. (2006). Teaching styles versus learning styles in the Accounting sciences in the United Kingdom and South Africa: A comparative analysis. Meditari Accountancy Research, I4(2):97-II2.

World Bank. [Accessed 23 January, 20II];Education and HIV|AIDS: A window of hope. 2002 Available: http:// siteresources.worldbank.org/EDUCATION/Resources 1278200-I099079877269/547664-I099080042112/Edu_HIVAIDS_window_hope.pdf.

Zajacova, A., Lynch, S.M., \& Espenshade, T.J. (2006). Self-efficacy, Stress and Academic Success in Collage. Research in Higher Education. 46(6):677-706. 